
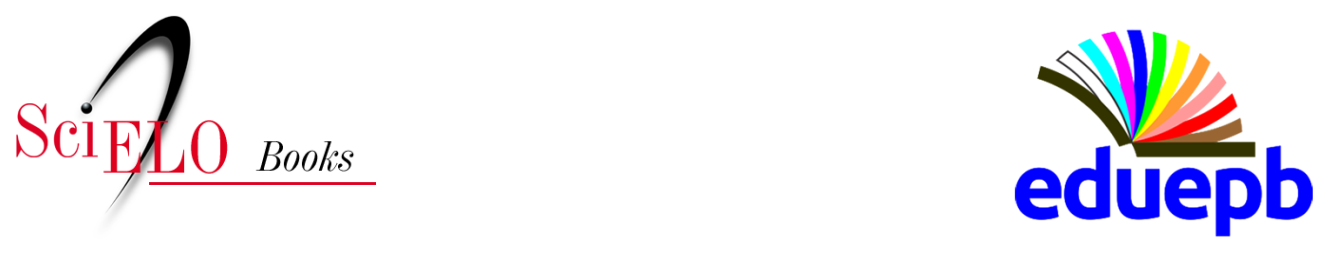

\title{
Mobilidade Humana e Migração
}

\author{
Andrea Pacheco Pacífico \\ Andrezza Teles Pinheiro \\ Júlia Patrícia Ferreira de Vasconcelos Granja \\ Adolfino Varela
}

\section{SciELO Books / SciELO Livros / SciELO Libros}

PACÍFICO, A. P., PINHEIRO, A. T., GRANJA, J. P. F. V., and VARELA, A. Mobilidade Humana e Migração. In: O Estado da Arte sobre Refugiados, Deslocados Internos, Deslocados Ambientais e Apátridas no Brasil: atualização do Diretório Nacional do ACNUR de teses, dissertações, trabalhos de conclusão de curso de graduação em João Pessoa (Paraíba) e artigos (2007 a 2017) [online]. Campina Grande: EDUEPB, 2020. pp. 27-45. ISBN:978-6587171-12-8. https://doi.org/10.7476/9786587171128.0004.

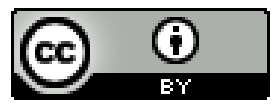

All the contents of this work, except where otherwise noted, is licensed under a Creative Commons Attribution 4.0 International license.

Todo o conteúdo deste trabalho, exceto quando houver ressalva, é publicado sob a licença Creative Commons Atribição 4.0.

Todo el contenido de esta obra, excepto donde se indique lo contrario, está bajo licencia de la licencia Creative Commons Reconocimento 4.0. 


\section{Mobilidade Humana e Migração}

Falar de mobilidade humana significa, a prori, falar de deslocamento, de fluxos, de jornadas, de dinamismo, de movimento etc. Para Knowles (2017, p.490), "[e]m suas muitas formas, pensar a mobilidade, essencialmente, coloca em primeiro plano o movimento, a dinâmica, a inquietação, a emergência e a conectividade, (re) conceitualizando o mundo social e as formas como ele funciona".

Em se tratanto de movimento, Botega (2017,p.496) defende que "os estudos de mobilidade social buscam compreender o movimento, ou seja, não o lugar em que o indivíduo está ou o que ele tem, mas, sim, de onde ele vem, para onde está indo e em que medida está chegando lá”. Nesse sentido, Botega (2017, p.497-500) também aponta que "a interface entre mobilidade social e migração internacional aparece na literatura a partir das trajetórias dos migrantes por algumas perspectivas", como sua incorporação no mercado de trabalho, integração social no local de destino e também das segundas gerações, estudo de remessas e projetos migratórios e de retorno.

Oliveira (2006) explana que, no contexto internacional, o debate relativo à mobilidade humana tem mais destaque nas políticas nacionais, sendo alocado no âmbito de fronteiras geopolíticas, uma vez que o migrante é considerado um revés para o país que o está recebendo. No entanto, essa mobilidade 
permite crescimento dos países mais ricos e empobrecimento dos países dos quais os migrantes saíram. Para Magagnin e Silva (2008, p.25),

[o] crescimento urbano desordenado, provocado pelo espalhamento espacial, o aumento excessivo no uso do automóvel, a falta de infra-estrutura urbana, a poluição do meio ambiente, entre outras, são questões que interferem na qualidade de vida da população. Estes fatores têm contribuído para que pesquisadores, decisores e tomadores de decisão busquem novas formas de minimizar, discutir e encontrar soluções para estas questões urbanas.

Segundo o ACNUR (2016), não existe uma definição para o termo migrante no âmbito internacional. Sendo este um termo mais genérico, diferentemente do termo refugiado.

"Migração" é comumente compreendida como um processo voluntário; por exemplo, alguém que cruza uma fronteira em busca de melhores oportunidades econômicas. Este não é o caso de refugiados, que não podem retornar às suas casas em segurança e, consequentemente, têm direito a proteções específicas no escopo do direito internacional (ACNUR, 2016).

O ACNUR (2016) relata ainda que confundir "migrantes" e "refugiados" desvia a importância da proteção legal que os indivíduos considerados refugiados precisam, tais como: 
proteção contra a famigerada repulsão, que muitas vezes é conferida a eles; e contra ser punido por buscar seu direito humano universal de requerer um local digno para residir, mesmo sem autorização e tendo que cruzar fronteiras de países vizinhos por necessidades extremas.

Segundo o ACNUR (2016), as possibilidades de migrações podem ser diversas. Os migrantes podem mover-se devido a desastres ambientais, pobreza, miséria, fome, violência; seja para irem em busca de condições de vida mais dignas, melhorias na educação, seja pela busca de melhores empregos, entre outros. Eles são protegidos pela norma internacional inserida nos direitos humanos. A falta dessa proteção pode acarretar em condições de trabalho insalubres e exploratórias, descriminações, servidão etc.

Já os migrantes escolhem se deslocar não por causa de uma ameaça direta de perseguição ou morte, mas, principalmente, para melhorar sua vida, buscando melhores oportunidades de trabalho e educação ou procurando viver com parentes que moram fora do país de origem. Diferentemente dos refugiados, que não podem voltar ao seu país, os migrantes continuam recebendo a proteção do seu governo. Para os governos, estas distinções são importantes. As nações tratam os migrantes de acordo com sua própria legislação e procedimentos em matéria de imigração, enquanto lidam com os refugiados segundo normas definidas a nível nacional e internacional (ACNUR, 2015). 
Em Matos (1993, p.2), podem-se analisar os tipos de migrantes segundo as fronteiras atravessadas por eles (tanto em âmbito nacional como internacional). Elas podem servir de análise para migrações em movimentos pendulares, movimentos periódicos, migrações de breve, média e longa duração.

[...] de residência, o vocábulo "migrar" tem sido utilizado para designar ora uma série de movimentos populacionais de duração, magnitude e longitude variáveis, ora apenas algum dos seus elementos. A razão para apenas se estudar determinados aspectos do fenômeno não será difícil de encontrar: envolvendo facetas tão díspares como a mudança de residência para o quarteirão seguinte ou a instalação dos pioneiros no Novo Mundo, o objeto de estudo "migração" não se mostra aprazível a uma análise unificadora, antes convida a estudos parciais e, frequentemente, unidimensionais.

Para Gonçalves (2001), migrações pendulares são a locomoção diária ou semanal de trabalhadores para grandes metrópoles, a fim de garantir trabalho e sobrevivência, enquanto movimentos periódicos ocorrem quando os trabalhadores deixam sua terra de origem e permanecem durante um período de tempo para realizar algum trabalho específico. Por fim, as migrações de baixa, média e longa duração vão depender do contexto e da finalidade da migração. 
Outro tipo de migrante, os chamados migrantes ambientais (também chamados de deslocados ambientais, refugiados ambientais, migrantes de sobrevivência etc.),

[...] são pessoas ou grupos de pessoas que, por razões de mudança súbita ou progressiva no ambiente que afetam suas vidas ou condições de vida, são obrigadas a deixar suas casas habituais, ou optam por fazê-lo, temporariamente ou permanentemente, e que se movem dentro do seu país ou no exterior (MATOS, 1993, p.4).

Segundo o ACNUR (2015), a mobilidade humana, particularmente resultante de mudanças climáticas, geralmente ocorre em território interno:

A maioria das mobilidades humanas devido às alterações climáticas é projetada para ocorrer dentro de fronteiras nacionais. Os princípios Orientadores em matéria de Deslocamento Interno reconhecem que as pessoas deslocadas têm direito a direitos humanos em seus países, incluindo proteção contra deslocamento forçado ou arbitrário. Contudo, pessoas que se deslocam através das fronteiras, apenas por razões ambientais, normalmente não gozam de proteção como refugiados nos termos da Convenção de 1951.

Quanto aos destinatários dos direitos de proteção, nesses casos, deve-se analisar a causa do deslocamento e perceber que 
os indivíduos levados ao deslocamento por causa de fatores climáticos, também possuem a necessidade da proteção.

Um tema dominante do discurso baseado em direitos é que os direitos não devem ser violados pelo deslocamento. Há, portanto, bem estabelecidas, normas internacionais, regionais e nacionais de instrumentos jurídicos e convênios para proteger os direitos das pessoas deslocadas pelos conflitos, perseguições, catástrofes naturais e projetos de desenvolvimento. Assim é surpreendente que um quadro semelhante para proteger os direitos de pessoas forçadas ao deslocamento por causa da mudança climática induzida não exista (GAUDÊNCIO; PACÍFICO, 2014 apud ZETTER).

Os chamados migrantes "permanentes" representam "um movimento de pessoas entre duas unidades administrativas, envolvendo uma estadia superior a um ano" (MATOS, 1993, p.3), e podem ser classificados em voluntários (migrações voluntárias individuais, familiares ou de grupos) e forçados (deportação ou êxodo, promovido por catástrofe natural, ecológica, razões políticas ou causa bélica). Os migrantes também podem invocar motivos diversos, como busca por melhorias de trabalho; saúde; questões familiares; motivos de estudos; ideologias políticas, religiosas ou étnicas; e catástrofes em geral.

A situação da crise mundial dos migrantes forçados ou deslocados é tão gritante na atual sociedade internacional que a Assembleia Geral da ONU deverá assinar, em setembro 
de 2018, em New York, o Pacto Global para Refugiados, um marco regulatório sobre deslocamento forçado, com foco não somente em refugiados, mas também em deslocados internos, deslocados ambientais e apátridas, focos desta pesquisa.

\section{Refugiados}

De acordo com a Convenção ONU relativa ao Estatuto dos Refugiados (de 1951), em seu art. 1 (A) (2), c/c o Protocolo adicional de New York (de 1967),

[s]ão refugiados as pessoas que, devido a fundados temores de perseguição por motivos de raça, religião, nacionalidade, grupo social ou opiniões políticas, encontrem-se fora de seu país de nacionalidade e não possam ou não queiram acolher-se à proteção de tal país; e, não tendo nacionalidade e estando fora do país onde antes teve residência habitual, não possam ou não queiram regressar a ele, em função das circunstâncias descritas.

Logo após a Segunda Guerra Mundial, como o problema dos refugiados não tinha sido resolvido, sentia-se a necessidade de um novo instrumento internacional que definisse a condição jurídica dos refugiados.

Os tratados internacionais e as organizações para protegerem os refugiados foram estabelecidos após a Segunda Guerra Mundial para proteger pessoas que escapam da perseguição direcionada por seus próprios governos. No entanto, a natureza 
do deslocamento transfronteiriço se transformou dramaticamente desde então. Certas ameaças, como mudanças ambientais, insegurança alimentar e violência generalizada levam um número enorme de pessoas a fugir de Estados, que são incapazes ou não querem garantir seus direitos básicos, assim como as condições em estados fracos e frágeis que possibilitam a privação de direitos humanos. Como essas razões não atendem à compreensão legal da perseguição, as vítimas dessas circunstâncias geralmente não são reconhecidas como "refugiados", impedindo as instituições atuais de garantirem sua proteção.

Um refugiado, conforme o atual regime internacional criado, em 1951, tem direito a um acolhimento seguro e a não devolução ao estado de perseguição. Contudo, a proteção internacional deve abranger mais do que a segurança física. Os refugiados devem usufruir, pelo menos, dos mesmos direitos e da mesma assistência básica que qualquer outro estrangeiro residindo legalmente no país, incluindo direitos fundamentais inerentes a todos os indivíduos.

O refugiado também tem obrigações gerais ao chegar aos países acolhedores. (ACNUR, 2017). O art. $2^{\circ}$ da Convenção supracitada reza que o refugiado também tem deveres para com o país em que se encontra, os quais compreendem notadamente a obrigação de se conformar às leis e aos regulamentos, assim como às medidas tomadas para a manutenção da ordem pública. Considere-se ser desejável que todos os refugiados abrangidos na definição da Convenção de 1951 possam gozar de igual estatuto.

Ainda, segundo Ramirez e Moraes (2017, p.619), "o ACNUR considera que a interpretação dos motivos da Convenção de 1951 deve ser global e suficientemente flexível para abranger grupos emergentes e responder de forma 
adequada a novos riscos de perseguição", o que explica a criação de regimes regionais de proteção aos refugiados, como o africano, via Convenção da OUA (Organização da Unidade Africana) (1969), e latino-americano, via Declaração de Cartagena (1984), que ampliaram a definição da Convenção de 1951 para reconhecer como refugiados aqueles que fogem por violação maciça de direitos humanos, coadunando-se com as necessidades locais. Saliente-se, em se tratando de América Latina, que esta é uma das poucas regiões do mundo onde a relação entre crime e migração forçada começou finalmente a ser estudada. Segundo Cantor e Serna (2017, p.1), “em parte, isso reflete os altos níveis de extrema violência ligados à criminalidade organizada na região desde a última década, como violência relacionada a gangues nos países do Triângulo Norte" (Honduras, Guatemala e El Salvador), "que se compara aos conflitos armados tradicionais". Segundo os autores (2017, p.2), no México há casos de deslocamento forçado de indivíduos resultante de grupos ligados a tráficos de drogas e na Colômbia resultante da dinâmica do crime organizado. No Brasil, a orientadora desta pesquisa tem lidado, na vida profissional, com casos de brasileiros solicitantes de refúgio em outros países como resultado da relação com o crime organizado.

Contudo, ainda em nível de Brasil, o país tem tradição na concessão de abrigo e proteção a pessoas perseguidas por motivos políticos, raciais e sociais. $\mathrm{O}$ instituto jurídico do refúgio no Brasil é regulado pela Lei 9.474/1997 que define os mecanismos para implementação do Estatuto dos Refugiados no Brasil (ACNUR, 2005).

A Lei 9.474/97 concede aos refugiados direitos e deveres específicos, diferenciados dos direitos conferidos e exigidos aos estrangeiros, tratando do pedido de refúgio; das proibições ao 
rechaço e à deportação e, ainda, regula a extradição e a expulsão dos refugiados.

Os refugiados encontram também proteção à luz do direito internacional, pois a condição de refugiado decorre de violações de direitos humanos básicos que se encontram consagrados na Declaração Universal dos Direitos Humanos de 1948. A todos é assegurado, com base na Declaração de 1948, o direito fundamental de não sofrer perseguição por motivos de raça, religião, nacionalidade, participação em determinado grupo social ou opiniões políticas (ACNUR, 2017).

A Carta das Nações Unidas (1945), fundamentada no princípio da proteção e do respeito dos direitos do ser humano e, como corolário desse princípio, o direito de asilo, busca conscientizar os Estados a garantir as liberdades fundamentais a todos sem distinção, incluindo-se os refugiados.

A título de ilustração (MJ, 2018), entre os cerca de 65,6 milhões de pessoas deslocadas no mundo, ou seja, uma em cada 113 pessoas, ao final de 2016, segundo o ACNUR, 22,5 milhões eram refugiados e 2,8 milhões eram solicitantes de refúgio. E, no Brasil, desde o advento da Lei 9474/1997 até dezembro de 2017, o Brasil já reconheceu 10.145 refugiados (sendo 587 em 2017), sendo que, destes, apenas 5.134 ainda residem no território nacional.

Ao número acima, segundo o MJ (2018), adicione-se ainda 86.007 solicitações de refúgio em andamento desde 1997 (sendo 33.866 em 2017). Entre estes, somente em 2017, foram 17.865 solicitações de venezuelanos, o maior número. Quanto aos reassentados, entre 2007 e 2017, segundo o MJ (2018), o Brasil reassentou 6.259 refugiados, sendo 504 deles colombianos. 
Saliente-se que os haitianos que fugiram do Haiti entre 2010 e 2017, devido ao terremoto de 2010, não foram reconhecidos como refugiados no Brasil, mas, sim, receberam visto permanente por razões humanitárias (mais de $50 \mathrm{mil}$ ), conforme resoluções do Conselho Nacional de Imigração (CNIg) 97/2012 e posteriores, ficando estes indivíduos afastados da proteção do regime nacional de refugiados.

\section{Deslocados Internos}

De acordo com os Princípios Orientadores relativos aos Deslocados Internos (1998),

os deslocados internos são pessoas, ou grupos de pessoas, forçadas ou obrigadas a fugir ou abandonar as suas casas ou seus locais de residência habituais, particularmente em consequência de, ou com vista a evitar, os efeitos dos conflitos armados, situações de violência generalizada, violações dos direitos humanos ou calamidades humanas ou naturais, e que não tenham atravessado uma fronteira internacionalmente reconhecida de um Estado.

Segundo Chetail (2017, p.205), embora sejam apenas princípios orientadores, e não um tratado juridicamente vinculante, "ele tem sido fundamental em prover uma compreensão convencional do termo "deslocados ambientais" e em identificar seus direitos e garantias baseados no direito internacional humanitário e nos direitos humanos", acrescentando que vários 
Estados têm incorporado essa definição com os princípios de proteção em suas legislações domésticas.

$\mathrm{Na}$ Declaração de Cartagena (1984), em nível de América Latina, é manifestada, pela primeira vez, a preocupação pela situação das pessoas deslocadas dentro de seu próprio país. Ademais, foi chamada a atenção das autoridades nacionais e das Organizações Internacionais competentes para que ofereçam proteção e assistência a estas pessoas e contribuam para aliviar a situação de calamidade em que muitas delas se encontram. (DECLARAÇÃO DE CARTAGENA, 1984. Art. III). E, em nível de continente africano, a Convenção de Kampala (2009), que visa à proteção e à assistência dos deslocados internos na África.

Lamentavelmente, não existe uma Organização Internacional ou um tratado juridicamente vinculante que preste serviço especificamente a eles, ou seja, os deslocados internos permanecem, portanto, sob proteção legal de seu próprio governo, ainda que esse mesmo governo possa ser a causa da fuga. A situação dos deslocados internos deve ser entendida como de alta vulnerabilidade, haja vista as condições reais e concretas em que vivem e as questões psicológicas desencadeadas pela experiência ameaçadora que originou o deslocamento (SOUZA, 2011, p.62).

O ACNUR não trabalha diretamente com os deslocados internos, mas, devido ao mandato ampliado pela Assembleia Geral da ONU, esta agência tem amparado milhões de deslocados internos por meio de uma estratégia chamada Abordagem Setorial ou Cluster approach, levando o ACNUR a supervisionar as necessidades de abrigo e proteção dos deslocados internos, haja vista que esses deslocados mantêm todos os seus direitos 
como cidadãos e são protegidos pelos Direitos Humanos e pelo Direito Internacional Humanitário.

Segundo o Internal Displacement Monitoring Centre (IDMC, 2017),

there were 6.9 million new internal displacements by conflict and violence in 2016. SubSaharan Africa overtook the Middle East as the region most affected, with almost one million new displacements in the Democratic Republic of Congo as a result of violent clashes in the provinces of North Kivu, South Kivu and Kasai. There were 24.2 million new displacements by disasters in 2016. As in previous years, South and East Asia were the regions most affected. While China, India and the Philippines have the highest absolute numbers, small island states suffer disproportionately once population size is taken into account.

Diferententemente dos refugiados, que são protegidos por um instrumento jurídico vinculante, os deslocados internos não o são. Por outro lado, o conceito de deslocado interno inclui deslocados ambientais, mesmo que a mobilidade não ultrapsse as fronteiras do país de origem ou de residência ou de nacionalidade, diferentemente da definição de refugiado, que exclui a proteção aos deslocados por mudança climática ou degradação ambiental, não havendo, ademais, ampliação do mandato do ACNUR para protegê-los. 


\section{Deslocados Ambientais}

Segundo a OIM (Organização Internacional para as Migrações) (2012), conforme citado por Pacífico (2012,p.126), "[o] termo deslocado ambiental se insere no contexto dos estudos migratórios, ao lado dos diversos tipos de migrantes, como refugiados, deslocados internos, e migrantes econômicos, cujos números globais, segundo a OIM, são estimados em 214 milhões".

A edição do relatório tendências globais, do ACNUR (GLOBAL TRENDS, 2016), o maior levantamento da Organização em matéria de deslocamento, revela que, ao final de 2016, havia cerca de 65,6 milhões de pessoas forçadas a deixar seus locais de origem por diferentes tipos de conflitos - mais de 300 mil em relação ao ano anterior. Esse total representa um vasto número de pessoas que precisam de proteção no mundo inteiro.

Encontrar soluções duradouras que permitam o deslocamento de pessoas para reconstruírem suas vidas e viverem com dignidade e paz é parte fundamental do mandato do ACNUR. Convencionalmente, soluções duráveis incluem repatriamento voluntário, reassentamento em um terceiro país e integração local. Essas abordagens provaram ser parcialmente inadequadas, pois há um crescente número de pessoas sob proteção do ACNUR em situações precárias de proteção e com pouca esperança de uma solução duradoura no futuro (ACNUR, 2017).

Assim, em 19 de setembro de 2016, os Estados-membros da ONU adotaram a "Declaração de Nova York para os Refugiados e Migrantes", comprometendo-se a desenvolver uma estrutura abrangente de resposta a refugiados $(\mathrm{CRRF})$ para emergências e situações prolongadas de deslocamento forçado. Este foi um 
reconhecimento de que abordagens abrangentes específicas da situação são necessárias para encontrar soluções duráveis, em conjunto com diversos atores, como governos, agências humanitárias, atores de desenvolvimento e refugiados. Um objetivo fundamental do CRRF é incentivar uma maior cooperação internacional para garantir proteção e encontrar soluções para refugiados, além de identificar novas abordagens e caminhos para proteção e soluções.

Já para administrar mundialmente os deslocados ambientais, segundo a Declaração acima, deveria ser criada uma Agência Mundial para os Deslocados Ambientais (AMDA), com a missão principal de conduzir os trabalhos de prospecção sobre a evolução do fenômeno dos deslocados ambientais, assim como avaliar políticas nacionais e internacionais, mobilizar eventos, avaliar programas e dar suporte aos deslocados nos diferentes pontos do globo (SEABRA, 2012, p.126).

"Normas e instituições têm sido criadas para proteger os migrantes e seus direitos em nível internacional, regional e local, mas a soberania dos estados muitas vezes produz barreiras às proteções" (PACÍFICO, 2012, p.125). Dessa forma, os Estados não estão contribuindo para as proteções dos que mais precisam atualmente, como os deslocados ambientais, "também chamados de refugiados ambientais [ou] indivíduos que não conseguem garantir condições de vida segura em seus locais de origem devido a secas, erosão dos solos, desertificação, sendo necessário um refúgio urgente em outro local" (PACÍFICO, 2012, p.126).

Como dito, a Convenção sobre o Estatuto dos Refugiados (1951) surge como um instrumento internacional específico de proteção dos direitos dos refugiados enquanto pessoa humana, excluindo os "refugiados/migrantes/deslocados ambientais", 
reconhecidos como indivíduos ou grupos de pessoas que migram de seu habitat original, temporária ou permanentemente, para um novo lar dentro de suas fronteiras nacionais, ou no exterior, em busca de uma outra qualidade de vida, não podendo assegurar uma vida segura em suas pátrias por causa de secas, erosão do solo, desertificação e/ou outros problemas ambientais. Em seu desespero, eles sentem que não têm outra alternativa, senão a de procurar acolhimento noutros países, mesmo que isto seja uma alternativa perigosa.

A OIM (2007) utiliza o termo migrante ambiental para se referir às pessoas que migram, temporária ou permanentemente, no país ou no exterior, em virtude de "mudanças bruscas ou progressivas no ambiente" de modo a afetar negativamente suas vidas. Nesta conceituação, os deslocados ambientais podem ser internos ou internacionais, temporários ou permanentes, podendo optar entre saírem do local de origem ou serem obrigados a deixá-lo, por ausência de meios de sobrevivência, e, por fim, eles não se deslocam somente devido a um evento ambiental, mas também por causa de conflitos políticos, econômicos ou sociais com ligação ambiental.

\section{Apátridas}

Segundo a Convenção do Estatuto de Apátridas (1954), apatridia é não possuir nacionalidade ou cidadania, ou seja, é quando inexiste o vínculo legal entre indivíduo e Estado. Assim, nacionalidade é um vínculo político entre o Estado soberano e o indivíduo, que faz deste um membro da dimensão pessoal do Estado. $\mathrm{O}$ art. 15 da Declaração Universal dos Direitos Humanos proclama que "todo homem tem direito a uma nacionalidade”. É regra no Direito Internacional que cada 
Estado tem a competência para disciplinar a forma de aquisição de sua nacionalidade. No Brasil, por exemplo, este tema se encontra regulado pelo art. 12 da Constituição da República de 1988 e pela Lei de Migração (Lei no 13.445/2017).

De acordo com o ACNUR (2012), contudo, as principais causas da apatridia são as políticas discriminatórias contra minorias, as falhas legislativas quanto à nacionalidade e os conflitos entre as leis vigentes dentro do Estado ou entre Estados.

O ACNUR (2012) afirma que existem dois tipos de apatridia: de jure e de facto. Apátridas de jure não são considerados nacionais sob as leis de nenhum Estado. Já os apátridas de facto são aqueles indivíduos que possuem formalmente uma nacionalidade, mas esta se caracteriza como ineficaz. Na prática, é quando um indivíduo tem seus direitos negados, por exemplo, um indivíduo que teve seu retorno para o país de origem negado, sendo esse direito usufruído por todos os nacionais.

Cotidianamente, os apátridas enfrentam grandes dificuldades, pois são impossibilitados de acessarem serviços de saúde e educação, de deslocarem-se livremente e obterem direito à propriedade. Também, de acordo com o ACNUR (2012), eles são suscetíveis a tratamento arbitrário, detenção e tráfico. Sendo colocados à margem da sociedade, eles podem gerar tensões que criem instabilidade em nível internacional, podendo provocar deslocamentos, assim como também causar uma perturbação nas suas vidas, haja vista que possuir uma nacionalidade é fundamental para a ampla participação na sociedade e uma condição necessária para usufruir dos direitos estatais e dos Direitos Humanos em si.

Enquanto o artigo $2^{\circ}$ da Declaração Universal dos Direitos Humanos (1948) afirma que os Direitos Humanos devem ser 
usufruídos por todos, existe, em contrapartida, o fato de que alguns direitos, como o direito ao voto, são limitados apenas aos nacionais. Um ponto ainda mais alarmante é porque muitos direitos dos apátridas são violados, ficando eles frequentemente impossibilitados de obterem documentos de identidade. Há uma grande possibilidade de serem detidos por não possuírem uma nacionalidade, além de não poderem ter o acesso à educação, aos serviços de saúde e lhes serem escassas oportunidades de emprego digno (ACNUR, 2012).

A ONU adotou a Convenção Sobre o Estatuto dos Apátridas, supracitada, que define apatridia, elenca as obrigações do apátrida (art. $2^{\circ}$ ) e as obrigações do Estado contratante da Convenção ( $\operatorname{art} .3^{\circ}$ e $5^{\circ}$ ), direito de propriedade do apátrida e suas atividades lucrativas, bem-estar, medida administrativas cabíveis ao Estado, expulsão (art. 31) e naturalização (art. 32).

Saliente-se que as dificuldades e as violações de direitos humanos que os apátridas sofrem podem ser evitadas por meio do preenchimento de lacunas nas legislações nacionais quanto à nacionalidade, como fornecer certidão de nascimento aos nascidos em seu território.

O ACNUR, então, foi encarregado de trabalhar concomitantemente com os governos para prevenir e solucionar os casos de apatridia, assim como foi incumbido de resguardar os direitos dos apátridas. No que se refere à atuação da Assembleia Geral da ONU, esta criou a Convenção para Redução dos Casos de Apatridia de 1961, que reza, entre outros: formas de concessão, perda e mudança e privação de nacionalidade pelos Estados (art. $1^{\circ}$ a $4^{\circ}, 8^{\circ}$ a 10 ). Contudo, a falta de precisão destas medidas leva o ACNUR (GLOBAL TRENDS, 2016) a estimar que haja aproximadamente dez milhões de apátridas em dezenas de países da África, da Ásia, das Américas e da Europa. 
Como exemplo, o Oriente Médio, por possuir sua base legislativa apoiada em ideias discriminatórias de gênero, cria diversas situações de apatridia. Outro exemplo, a Europa, após a dissolução da URSS e da Federação Iugoslava, nos anos 1990, criou várias situações de apatridia nos novos países, conforme os vários exemplos citados na Forced Migration Review 32 (2009).

Recentemente algumas experiências obtiveram êxito no que se refere à dificuldade de nacionalização que os apátridas encontram, como na Ásia, onde milhões de pessoas receberam sua nacionalidade no Bangladesh (HUSSAIN, 2009, p.30-31) e no Nepal (WHITE, 2009, p.28-29). Contudo, apesar da grande redução do número de apatridia, no Himalaia ainda existem cerca de 800.000 pessoas sem nacionalidade confirmada e impossibilitadas de terem acesso a serviços públicos pela sua invisibilidade jurídica.

Destarte, além dos esforços onusianos e de alguns estados isolados para prevenirem e reduzirem apatridia, Gyulai (2009, p.48-49) defende que os Estados também deveriam estabelecer mecanismos de identificação e de proteção para os apátridas em seus territórios, como o Brasil, que, recentemente, em sua Lei de Migração (Lei 13.445/2017), simplificou o procedimento para aquisição de nacionalidade brasileira de indivíduos apátridas residentes no país.

Em nível de Brasil, entrou em vigor, em 2017, a Lei 13.445, c/c o decreto 9.199/2018, que reza que o Brasil pode reconhecer um estrangeiro como apátrida e, após dois anos de residência, naturalizá-lo, reduzindo casos de apatridia e facilitando a naturalização. 